\title{
HIV-1 epidemiology and circulating subtypes in the countryside of South Brazil
}

\author{
Carina Sperotto Librelotto[1], Tiago Gräfi[2],[3], Daniel Simon ${ }^{[1],}$ \\ Sabrina Esteves Matos de Almeida ${ }^{[3]}$ and Vagner Ricardo Lunge ${ }^{[1]}$
}

[1]. Programa de Pós-Graduação em Biologia Celular e Molecular Aplicada à Saúde, Universidade Luterana do Brasil, Canoas, Rio Grande do Sul, Brasil. [2]. Programa de Pós-Graduação em Biotecnologia e Biociências, Universidade Federal de Santa Catarina, Florianópolis, Santa Catarina, Brasil. [3]. Centro de Desenvolvimento Técnico e Científico, Fundação Estadual de Produção e Pesquisa em Saúde, Porto Alegre, Rio Grande do Sul, Brasil.

\begin{abstract}
Introduction: Human immunodeficiency virus type 1 (HIV-1) has spread worldwide, with several subtypes and circulating recombinant forms. Brazil has an incidence of $20.5 \mathrm{HIV}-1$ /acquired immunodeficiency syndrome (AIDS) patients per 100,000 inhabitants; however, the Southernmost State of Rio Grande do Sul (RS) has more than twice the number of HIV-1-infected people (41.3/100,000 inhabitants) and a different pattern of subtype frequencies, as previously reported in studies conducted in the capital (Porto Alegre) and its metropolitan region. This study examined HIV-1/AIDS epidemiological and molecular aspects in the countryside of Rio Grande do Sul. Methods: Socio-demographic, clinical and risk behavioral characteristics were obtained from HIV-1-positive adult patients using a structured questionnaire. HIV-1 subtypes were determined by nested-polymerase chain reaction (PCR) and sequencing of the pol and env genes. Results: The study sample included 149 (55\% women) patients with a mean age of $41.8 \pm 11.9$ years. Most (73.8\%) patients had a low education level and reported heterosexual practices as the most $(91.9 \%)$ probable transmission route. HIV-1 subtypes were detected in 26 patients: 18 (69.2\%) infected with subtype C, six (23.1\%) infected with subtype B and two (7.7\%) infected with BC recombinant forms. Conclusions: These data highlight the increasing number of HIV-1 subtype C infections in the countryside of South Brazil.
\end{abstract}

Keywords: HIV-1. Epidemiology. Subtypes. South Brazil.

\section{INTRODUCTION}

Approximately 35 million people worldwide are infected with human immunodeficiency virus (HIV), the etiological agent of acquired immunodeficiency syndrome (AIDS) ${ }^{(1)}$. The global AIDS pandemic is a composite of multiple HIV epidemics, each occurring in specific geographic regions and populations. The main (M) group of HIV type 1 viruses is responsible for the majority of AIDS cases and has 9 subtypes (classified with the letters A-D, F-H, J and K) with a complex distribution worldwide. Furthermore, recombinant viruses can appear in regions where different subtypes are prevalent. Subtypes A1, B, C and the recombinant form CRF02_AG are the most prevalent HIV-1 forms and are associated with more than $75 \%$ of AIDS cases worldwide ${ }^{(2)}$.

There are at least 734,000 people living with HIV-1/ AIDS in Brazil, most of whom are infected with subtype $\mathrm{B}^{(3)}$.

Corresponding author: Dr. Daniel Simon. Programa de Pós-Graduação em Biologia Celular e Molecular Aplicada à Saúde/ULBRA. Av. Farroupilha 8001, Prédio 22/5a andar, Bairro São José, 92425-900 Canoas, Rio Grande do Sul, Brasil.

Phone: 5551 3477-9219

e-mail: daniel.simon@ulbra.br

Received 16 March 2015

Accepted 20 May 2015
The subtypes $\mathrm{C}, \mathrm{F} 1$ and the recombinants $\mathrm{BC}$ and $\mathrm{BF}$ are usually observed at low frequencies in the majority of Brazilian cities and states ${ }^{(4)(5)(6)(7)(8)(9)(10)}$. The South Region (States of Rio Grande do Sul, Santa Catarina, and Paraná) contains $20 \%$ of Brazilian HIV-1/AIDS patients, with high rates of incidence (31.1 patients/100,000 inhabitants) and mortality ( 8.1 deaths $/ 100,000$ inhabitants) $)^{(3)}$. In contrast to other regions of the country, subtype $\mathrm{C}$ is the most frequent in the South $^{(11)(12)(13)(14)}$. The detailed dynamics of viral spread in this region are not well understood, although two phylogeographic studies have demonstrated the possible origin and dissemination routes for subtype $\mathrm{C}$ in the South region ${ }^{(15)(16)}$.

The prevalence and incidence rates of HIV-1 infection vary according to the modes of transmission in each population, usually reflecting socioeconomic, environmental and behavioral factors. High HIV-1 frequencies are mainly observed in populations at increased risk and vulnerability, such as injecting drug users (IDU), men who have sex with men (MSM) and female sex workers ${ }^{(17)}$. Socio-demographic (age, gender, education level, and economic condition) and behavioral variables (IDU and MSM) have already been investigated and associated with HIV-1/AIDS incidence and subtype frequency in Southern Brazilian states ${ }^{(12)(13)}$. Although many HIV-1/AIDS studies have been conducted in this region, data concerning the HIV-1 epidemic in the countryside remain scarce because published data are from the capitals (Porto Alegre, Florianópolis, 
and Curitiba), metropolitan areas (Canoas and Camboriú) and/ or harbor cities (Rio Grande, Imbituba, and Itajaí) (reviewed by Gräf \& Pinto) ${ }^{(14)}$. In the present study, the epidemiology and frequency of HIV-1/AIDS subtypes are described in the City of Cruz Alta - RS and the surrounding localities. This hinterland region has a high HIV-1 incidence (66 cases per 100,000 inhabitants $)^{(18)}$ and is located more than 300 kilometers away from the capital city of the state.

\section{METHODS}

\section{Study population and sample collection}

A cross-sectional study was conducted in a reference outpatient treatment center for HIV testing and AIDS treatment in Cruz Alta-RS. HIV-infected adults seeking medical treatment were consecutively enrolled in the study from July 2011 to August 2012. As show Figure 1 most patients lived in the Cruz Alta municipality, but some people were from neighboring towns (Fortaleza dos Valos, Ibirubá, Ijuí, Jacuizinho, Quinze de Novembro, Saldanha Marinho, Santa Bárbara do Sul, and Tupanciretã).

Socio-demographic and potential risk factors for HIV infection were obtained using a standardized individual questionnaire administered by a trained interviewer in a private room. General laboratory and clinical data were obtained from medical records. Blood samples were collected by venipuncture in $5 \mathrm{ml}$ tubes using ethylenediaminetetraacetic acid (EDTA), centrifuged to separate the plasma and the buffy coat in $2 \mathrm{ml}$ tubes and stored at $-20^{\circ} \mathrm{C}$.

\section{HIV-1 amplification, sequencing and subtyping}

Whole DNA was purified from peripheral blood mononuclear cells (PBMC) using the QIAmp Blood Kit (Qiagen Inc., Chatswoth, CA, USA). Amplification by nested polymerase chain reactions (nested-PCR) of the pol (the whole protease and part of the reverse transcriptase genes) and gp120 (C2-V3) env regions were performed as previously described with several modifications ${ }^{(19)}$. Briefly, the K1 and MMRT6 primers were used to amplify a pol gene fragment of approximately $1,505 \mathrm{bp}$ (nucleotides 2,147 to 3,650 of the HXB2 reference genome). The second amplification (nested) was conducted using primers DP16 and MMRT5 to amplify a fragment of approximately 1,325bp (nucleotides 2,251 to 3,575 of HXB2). The ED5 and ED12 primers were used to amplify a gp120 env region of $1,255 \mathrm{bp}$ (nucleotides 6,557 to 7,812 of HXB2). Nested-PCR was performed using the primers ED31 and ED33 to obtain a fragment of 566bp (nucleotides 6,817 to 7,382 of HXB2).

Next, the fragments were visualized on an agarose gel and purified as described previously ${ }^{(20)}$. Forward and reverse $p o l$ and env amplified strands were sequenced in an ABI 3130xl Genetic Analyzer (Applied Biosystems Inc., Norwalk, CT, USA). Quality analysis was performed using Sequencing Analysis

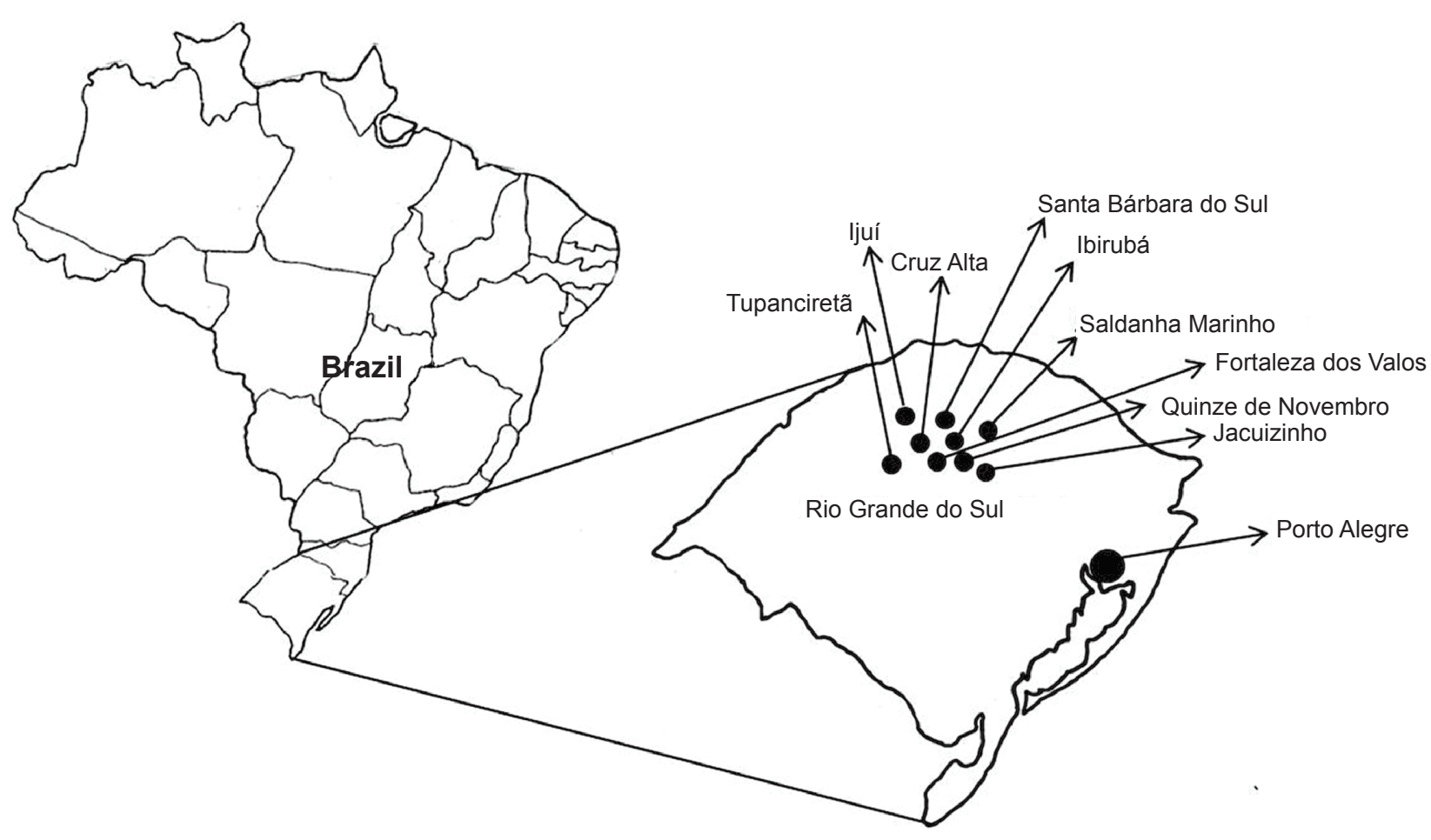

FIGURE 1 - Map of Brazil indicating the State of Rio Grande do Sul, with the location of the City of Cruz Alta, the neighboring towns and the State capital Porto Alegre. 
v.5.3.1 software (Applied Biosystems Inc., Norwalk, CT, USA) by evaluating the main technical parameters (i.e., raw data, electropherograms and the quality value of sequenced bases). Sequence data were submitted to GenBank with accession numbers KP224476-KP224501.

Chromatograms were assembled and visually assessed using SeqMan software, LaserGene package (DNAStar, Madison, WI, USA). Initial subtyping was performed with REGA HIV-1 Automated Subtyping Tool $2.0^{(21)}$ and Recombinant Identification Program (RIP) ${ }^{(22)}$. Phylogenetic trees were reconstructed by the maximum likelihood algorithm implemented in Phylogenetic Maximum Likelihood (PhyML) tool ${ }^{(23)}$. For the phylogenetic analysis, HIV-1 reference sequences were obtained from the Los Alamos HIV-1 Database and aligned by Muscle with the sequences from the current study ${ }^{(24)}$. Recombinant detection and bootscanning analysis were performed for all sequences using Simplot 3.5.1 software ${ }^{(25)}$.

\section{Statistical analysis}

Statistical analysis was performed using Statistical Package for the Social Sciences (SPSS) software, version 18.0 (SPSS Inc., Chicago, IL, USA). The results were expressed as the means and standard deviations $( \pm \mathrm{SD})$ or frequencies and percentages. Categorical variables were compared between groups and subtypes using Fisher's exact test or the chi-square test as recommended. Continuous variables were compared between groups using Student's $t$-test or the non-parametric Mann-Whitney $U$ test. The significance level was set at $\mathrm{p}<0.05$.

\section{Ethical considerations}

The study was approved by the Research Ethics Committees of the Universidade Luterana do Brasil (ULBRA) (protocol number: $2011-215 \mathrm{H}$ ). All participants signed an informed consent form.

\section{RESULTS}

\section{Epidemiology of HIV-1}

The study sample included a total of 149 HIV seropositive patients. The socio-demographic and epidemiological characteristics of the patients are shown in Table 1. Among the patients, $82(55 \%)$ were women, and the mean age was $41.8 \pm 11.9$ years. The men were significantly older than the women $(\mathrm{p}=0.015)$. A total of $110(73.8 \%)$ patients had completed only primary education or less. Sexual practices were mainly heterosexual (97.6\% in women; $85.1 \%$ in men; $\mathrm{p}=0.002)$. Six $(9 \%)$ men and no women reported homosexual relations, while four $(6 \%)$ men and one $(1.2 \%)$ woman reported bisexual practices. Women had a significantly lower average number of sexual partners during the past twelve months $(1.3)$ than men $(2.5)(p=0.004)$. The time since HIV diagnosis was a mean of $6.2 \pm 5.6$ years. A total of $40(26.8 \%)$ patients were HAART-naïve; these patients had a mean age of $36.0 \pm 11$ years and were mostly women $(60 \%)$.

The most common HIV transmission route was sexual intercourse $(85.9 \%)$, followed by blood transfusion $(4.7 \%)$, needle sharing (3.4\%) and sharp objects (1.3\%). Smoking and snorting drug use were significantly higher in men than in women. There was no significant difference in injecting drug use between men and women. The presence of tattoos was reported by $43(28.9 \%)$ individuals, and piercing was reported by only $10(6.7 \%)$ patients, with similar frequencies in men and women. Surgical history was reported by $99(66.4 \%)$ subjects in the study. A significantly higher proportion of women reported having undergone surgery $(86.6 \% v s .41 .8 \%)$ and blood transfusions $(31.7 \%$ vs. $17.9 \%)$ in the past than men $(\mathrm{p}<0.001$ and $p=0.034$, respectively). Furthermore, $27(32.9 \%)$ women became pregnant after being diagnosed with HIV. Eighteen $(66.6 \%)$ of those women received highly active antiretroviral therapy (HAART) during pregnancy, but five (18.5\%) did not undergo this treatment. There was no information about therapy in the medical records of the remaining four (14.9\%) women.

Sixteen (10.7\%) of the individuals had cluster of differentiation 4 (CD4) counts less than 200 cells/ml, including six (37.5\%) men and ten $(62.5 \%)$ women. Four of them (one man and three women) were HAART treatment-naïve. Fifty-three (35.6\%) of the individuals had at least one opportunistic disease. Oral candidiasis: in $14(9.3 \%)$ patients, herpes zoster: $8(5.3 \%)$, scabies: $7(4.7 \%)$ and pneumonia: 6(4\%) were the most frequent, while cryptosporidiosis, esophageal candidiasis, Pneumocystis jirovecii pneumonia and tuberculosis were the least frequent (two cases each).

\section{HIV-1 molecular diversity}

HIV subtypes were investigated only in HAART treatmentnaïve patients due to the high HIV loads necessary for sequencing and the low probability of detecting antiviral resistance mutations in these samples. A total of 26 of the 31 HAART treatment-naïve patients were investigated (analysis of the remaining five samples presented inconclusive results). The comparison between these 26 patients with the remaining 123 patients showed no difference in the majority of characteristics (Table 2). Highly significant differences $(\mathrm{p}<0.001)$ were observed only in viral load as expected due to the selection of treatment-naïve patients for subtyping.

The molecular diversity of the HIV-1 epidemic in the Cruz Alta region is represented by the phylogenetic tree in Figure 2. Among $26 \mathrm{pol}$ sequences, eighteen (69.2\%) samples were subtype C, six (23.1\%) were subtype B, and two (7.7\%) were unique recombinant forms (URF). Simplot analysis of the pol region demonstrated that these last two patients were HIV-1 subtype B and C URFs (both had an insertion sequence of a subtype $\mathrm{B}$ sequence in a subtype $\mathrm{C}$ backbone). The env region was sequenced for 24 of the 26 patients with sequences for the $p o l$ region. Phylogenetic analyses of the env sequences confirmed the findings of the pol gene sequences, although no intergenic recombination was found (data not shown).

Socio-demographic and epidemiological characteristics of HIV patients infected with subtypes B and C were compared. Significant differences were observed only for surgery history: a higher proportion of HIV subtype $\mathrm{C}$ patients $(66.7 \%)$ than subtype B patients $(16.7 \%)$ had undergone surgery $(\mathrm{p}=0.033)$. All other variables showed no significant differences (Table 3). 
TABLE 1 - Analysis of socio-demographic and epidemiological characteristics of HIV-positive patients.

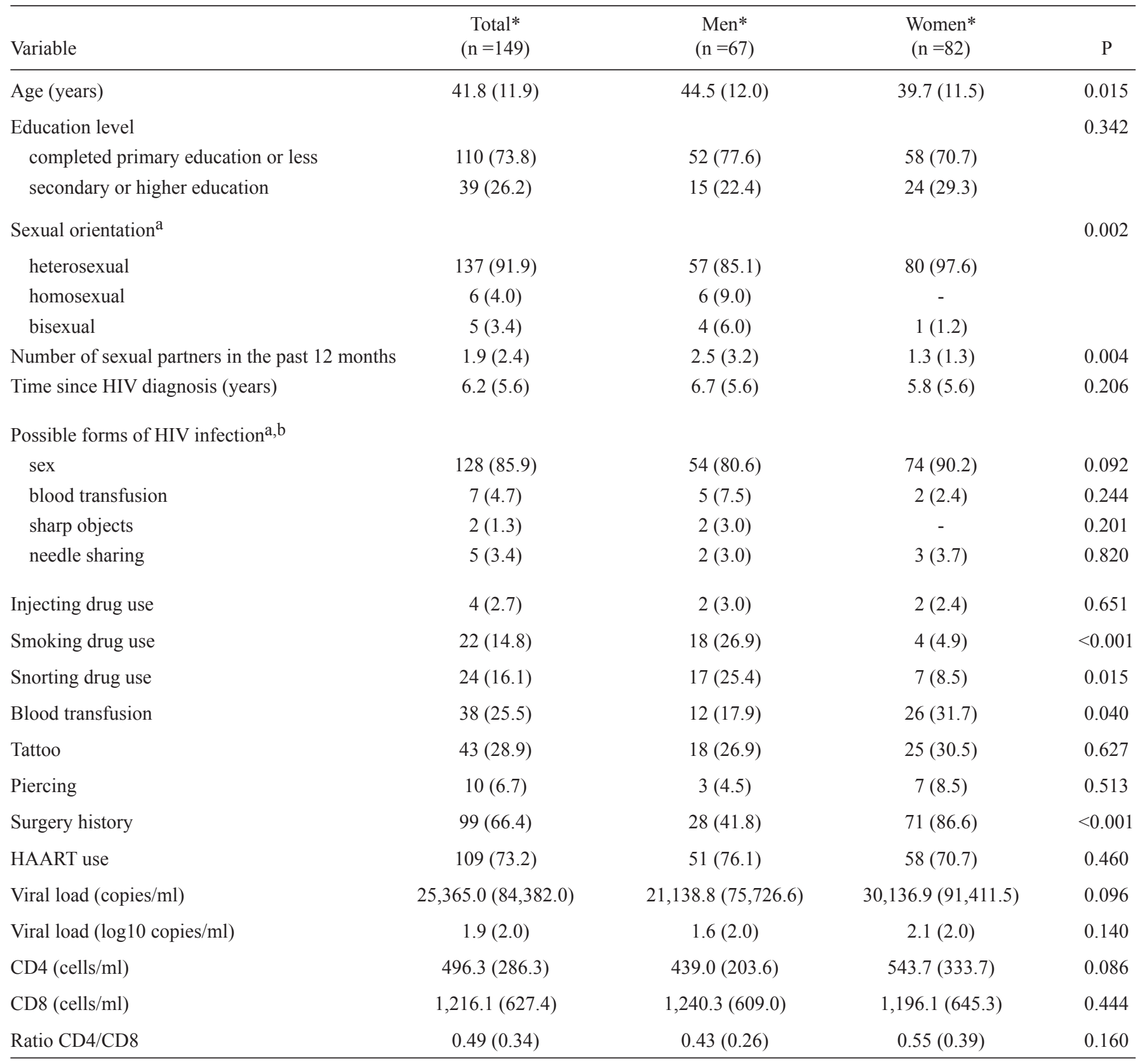

HIV: human immunodeficiency virus; HAART: highly active antiretroviral therapy; CD4: cluster of differentiation 4; CD8: cluster of differentiation 8 . *Data are shown as the number of patients (percentage), except for age, time of HIV diagnosis, number of sexual partners in the past 12 months, viral load, log viral load, CD4, CD8 and CD4/CD8 ratios, which are expressed as means (standard deviation - SD). ${ }^{\mathbf{a}}$ Totals do not coincide due to a lack of data from certain

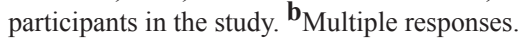

\section{DISCUSSION}

The HIV-1/AIDS epidemic has been extensively studied in the metropolitan regions of Brazil. However, the disease has emerged in the countryside during the last decade, and epidemiological data have demonstrated an increased incidence of HIV-1/AIDS in medium and small cities ${ }^{(26)}$. The present study focused on the epidemiology of HIV-1/AIDS in a small geographic region (Cruz Alta and neighboring towns) in the countryside of South Brazil.

The general epidemiological findings demonstrated that HIV-1/AIDS was detected predominantly (73.8\%) in patients with only primary education or less. Low education levels combined with low socioeconomic status, overcrowding and limited access to health services were previously associated with HIV-1 infection in Brazil (27) (28) (29). Another interesting finding was the advanced age $(41.8 \pm 11.9)$ of HIV-1/AIDS 
TABLE 2 - Analysis of socio-demographic and epidemiological characteristics of subtyped and non-subtyped HIV-positive patients.

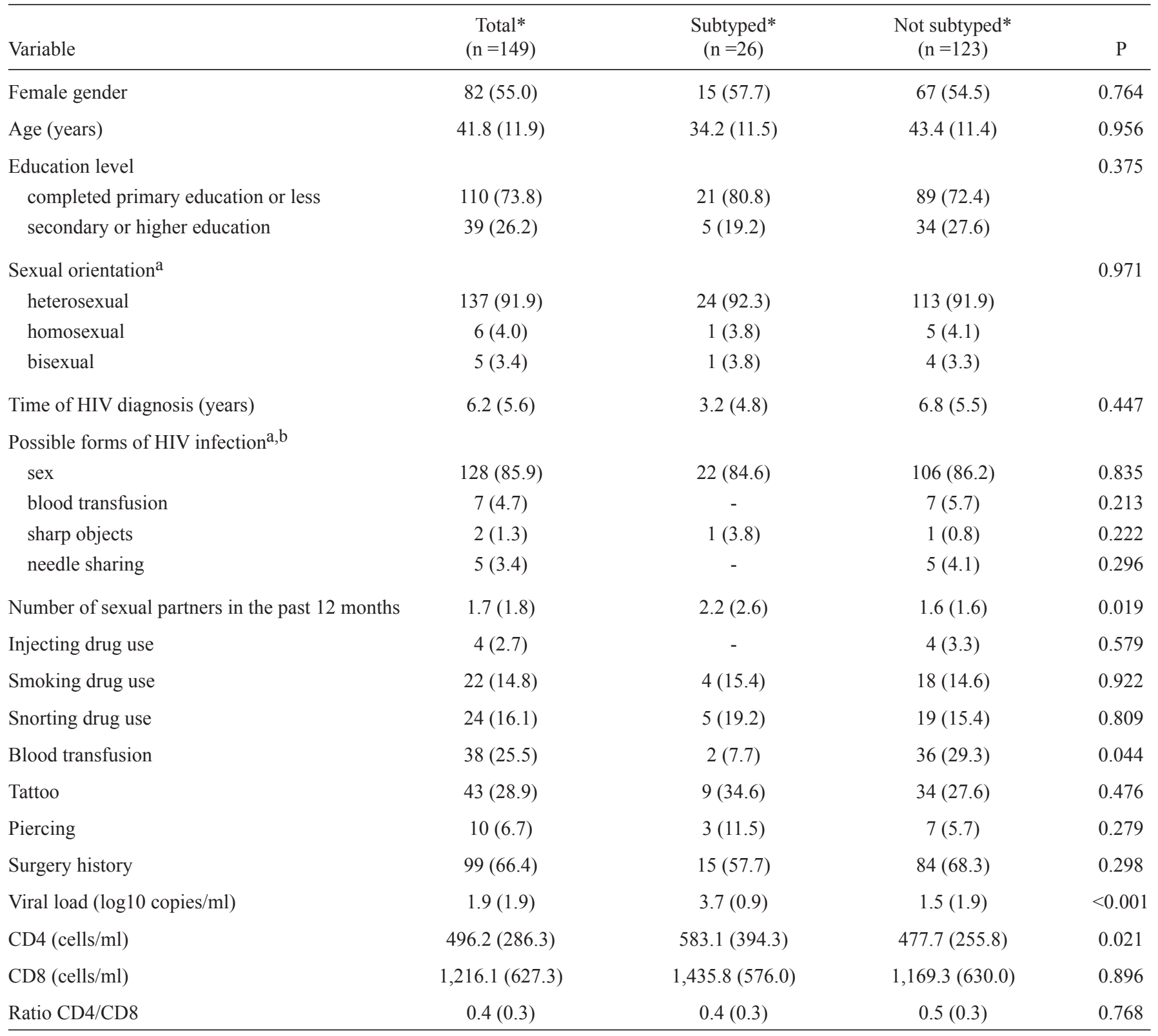

HIV: human immunodeficiency virus; CD4: cluster of differentiation 4; CD8: cluster of differentiation 8. *Data are shown as the number of patients (percentage), except for age, time of HIV diagnosis, number of sexual partners in the past 12 months, viral load, log viral load, CD4, CD8 and CD4/CD8 ratios, which are expressed as means (standard deviation - SD). ${ }^{\mathbf{a}}$ Totals do not coincide due to a lack of data from certain participants in the study. ${ }^{\mathbf{b}}$ Multiple responses.

patients (men were significantly older than women). In Brazil, the highest rates of HIV-1 infection were observed among individuals aged 30 to 49 years ${ }^{(18)(30)}$. Older individuals have a higher chance of infection than younger people because they have been exposed to risk situations for a longer period without access to preventive information ${ }^{(27)}$.

Another important epidemiological result was the high frequency of women (55\%) among the patients analyzed. Feminization of the epidemic was previously observed in the same state and other Brazilian regions and was associated with increasing HIV-1 heterosexual transmission since the beginning of the $21^{\text {st }}$ century ${ }^{(12)(31)(32)}$. Other studies have also reported the contribution of situations related to women's vulnerability (e.g., difficulty negotiating condom use with their partners, financial difficulties, and drug use before or during sex) to the increasing number of HIV-1-infected women in the last few years ${ }^{(33)(34)}$.

The feminization of the HIV epidemic also constitutes an important risk factor for vertical transmission. In our study, 27 (32.9\%) women became pregnant after HIV-1 infection, and approximately one-third of them did not receive HAART treatment during pregnancy. Similar results were observed by Lana \& Lima ${ }^{(35)}$, in which seven out of 22 pregnant patients $(24.2 \%)$ did not undergo HAART treatment in a study conducted in the Eastern District in the City of Belo Horizonte 
TABLE 3 - Analysis of socio-demographic and epidemiological characteristics in HIV-positive patients infected with subtypes B and C.

\begin{tabular}{|c|c|c|c|c|}
\hline Variable & $\begin{array}{l}\text { Total* } \\
(\mathrm{n}=24)\end{array}$ & $\begin{array}{l}\text { Subtype } B^{*} \\
\qquad(\mathrm{n}=6)\end{array}$ & $\begin{array}{l}\text { Subtype } C^{*} \\
\qquad(\mathrm{n}=18)\end{array}$ & $\mathrm{P}$ \\
\hline Female gender & $14(58.3)$ & $2(33.3)$ & $12(66.7)$ & 0.151 \\
\hline Age (years) & $34.8(11.8)$ & $30.3(7.2)$ & $35.3(12.9)$ & 0.119 \\
\hline Education level & & & & 0.772 \\
\hline completed primary education or less & $19(79.2)$ & $5(83.3)$ & $14(77.8)$ & \\
\hline Sexual orientation ${ }^{\mathrm{a}}$ & & & & 0.555 \\
\hline heterosexual & $23(95.8)$ & $6(100)$ & $17(94.4)$ & \\
\hline homosexual & $1(5.6)$ & - & $1(5.6)$ & \\
\hline Time of HIV diagnosis (years) & $3.4(5.0)$ & $3.6(5.1)$ & $3.4(5.2)$ & 0.993 \\
\hline sharp objects & $1(4.2)$ & - & $1(5.6)$ & \\
\hline Number of sexual partners in the past 12 months & $2.1(2.7)$ & $0.6(0.8)$ & $2.6(3.0)$ & 0.142 \\
\hline Smoking drug use & $3(12.5)$ & $1(16.7)$ & $2(11.1)$ & 0.722 \\
\hline Snorting drug use & $5(20.8)$ & $1(16.7)$ & $4(22.2)$ & 0.722 \\
\hline Blood transfusion & $2(8.3)$ & - & $2(11.1)$ & 0.394 \\
\hline Tattoo & $7(29.2)$ & $2(33.3)$ & $5(27.8)$ & 0.795 \\
\hline Piercing & $3(12.5)$ & $2(11.1)$ & $1(16.7)$ & 0.722 \\
\hline Surgery history & $13(54.2)$ & $1(16.7)$ & $12(66.7)$ & 0.033 \\
\hline
\end{tabular}

HIV: human immunodeficiency virus; CD4: cluster of differentiation 4; CD8: cluster of differentiation 8.*Data are shown as the number of patients (percentage), except for age, time of HIV diagnosis, number of sexual partners in the past 12 months, viral load, log viral load, CD4, CD8 and CD4/CD8 ratios, which are expressed as means (standard deviation - SD). ${ }^{\mathbf{a}}$ Totals do not coincide due to a lack of data from certain participants in the study. ${ }^{\mathbf{b}}$ Multiple responses.

(State of Minas Gerais, Brazil) from 2004 to 2005. These data demonstrate that the early identification of HIV-1-infected pregnant women remains low in $\operatorname{Brazil}^{(36)(37)}$.

The most probable HIV-1 transmission route (as reported by the patients) was sexual (85.9\%). This finding is in agreement with other Brazilian studies that highlighted the importance of this HIV-1 transmission route in men and women ${ }^{(27)(38)(39)(40)}$. In contrast, homosexual behavior was reported at a low frequency. There was also a low percentage of IDU $(2.7 \%$, with the same proportion of men and women), similar to the results of a study conducted in the countryside of the State of Rio de Janeiro. This finding suggests that injecting drug use is not one of the most important transmission routes in small cities ${ }^{(41)}$. This low prevalence of IDU could also explain the previously demonstrated low frequency of co-infection with HIV-1/AIDS and hepatitis $\mathrm{C}$ virus $(\mathrm{HCV})^{(42)}$.
Several subtypes and recombinant forms of HIV-1 group M are widely disseminated, with different frequencies according to geographic region. Recent studies have reported that subtype $\mathrm{C}$ and the recombinant form $\mathrm{BC}$ have a high prevalence in the South region of Brazil ${ }^{(14)(43)(44)}$. In our study, we observed a high prevalence of subtype C $(69.2 \%)$ and the occurrence of some $\mathrm{BC}$ recombinant forms. The circulating recombination form 31 (CRF31_BC), which is prevalent in 19-26\% of HIV-1 infections in Porto Alegre ${ }^{(14)}$, was not detected in Cruz Alta. The $\mathrm{BC}$ recombinant forms described here had close similarities to CRF31_BC; however, these sequences clustered outside of the CRF31_BC clade in a position between the subtype B and C clades in the phylogenetic tree, supporting their identification as unique recombination patterns in the bootscanning analyses. The high prevalence of pure subtype $\mathrm{C}$ in Cruz Alta was similar to the prevalence observed in State of Santa Catarina, where CRF31_BC was also observed at very low frequencies ${ }^{(20)(45)(46)}$. 

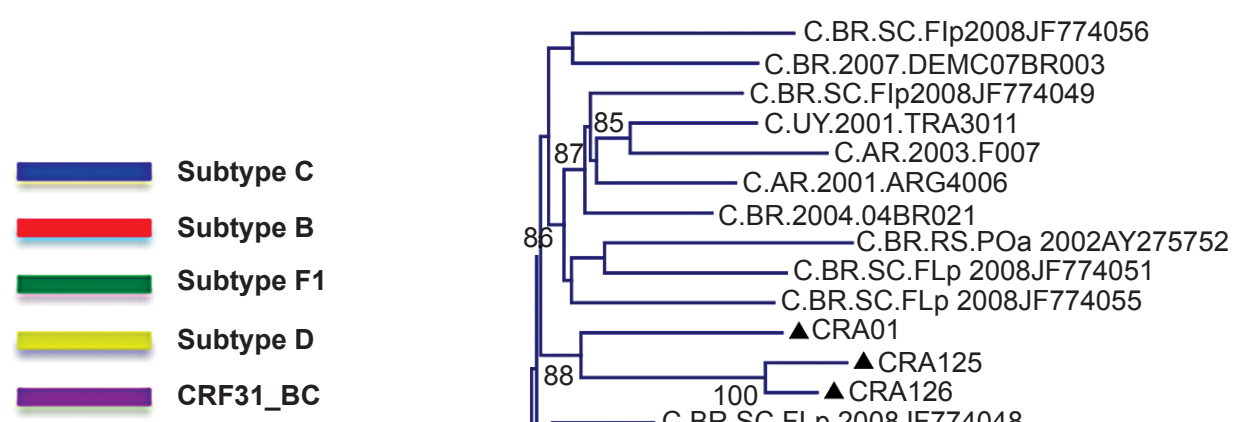

C.BR.SC.FLp 2008JF774048

C.BR.SC.POa 2002AY275755

C.BR.RS.POa 2005EF379168

C.BR.RS.FLp 2008JF774053

C.BR.RS.POa 2002AY275734

C.BR.RS.POa 2005EF379171

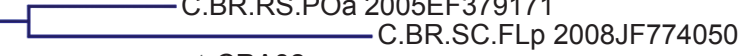

$\Delta 8$ CRA82

C.BR.SC.FLp 2008JF774057

$95-\Delta \mathrm{CRA} 11$

$94 \square \Delta$ CRA 116

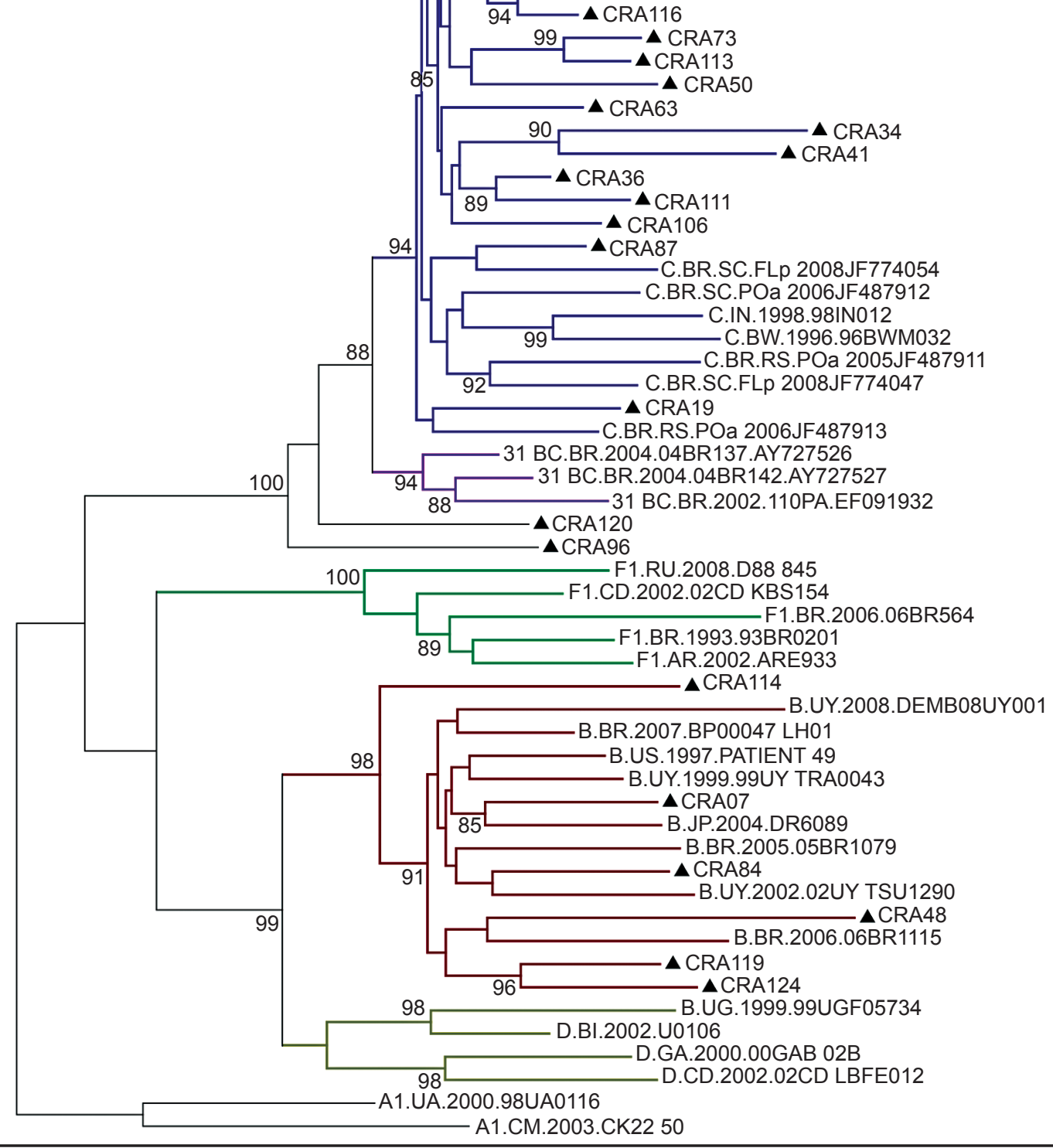

FIGURE 2 - Genetic diversity of the HIV-1 epidemic in Cruz Alta, State of Rio Grande do Sul. A maximum likelihood tree was constructed for the HIV-1 pol gene. Cruz Alta samples are marked with black triangles, SH-aLRT values for node support are shown (above 85\%), and subtype A1 sequences represent the outgroup. The tree branches are colored according to the legend on the top left. HIV-1: human immunodeficiency virus type 1; SH-aLRT: Shimodaira-Hasegawa approximate likelihood ratio test. 
The data shown here support the hypothesis that CRF31_BC is an HIV-1 form mainly restricted to Porto Alegre City and its metropolitan region.

Several factors may contribute to the dissemination of subtype C in the RS and South Region, including viral fitness (replication and evolutionary origin), the human host and the ecological dynamics of the AIDS epidemic. Some studies have suggested that HIV-1 subtype $\mathrm{C}$ is less virulent and that its disease progression is slower compared to other subtypes; asymptomatic infections are usually longer-lasting, with more opportunities for HIV-1 transmission ${ }^{(47)(48)(49)}$. This specific viral characteristic associated with easy heterosexual transmission could explain the current epidemiological scenario of Southern Brazil $^{(11)}$. However, a recent report demonstrated no significant difference in the clinical progression between patients infected with subtype $\mathrm{C}$ and other subtypes in a cohort of patients in this region $^{(50)}$. Nevertheless, investigations with longer follow-ups and larger population sizes are needed to elucidate the natural history of these subtypes and their disease progression ${ }^{(47)}$.

The present study was conducted in a region with high HIV-1 incidence. Thus, it is important to note that public health policies recently implemented for the prevention of HIV transmission (i.e., providing easy access to rapid diagnostic tests in primary healthcare and offering early treatment to all HIV-positive individuals ${ }^{(51)}$ may have contributed to the reduction in HIV infection rates in this region. Therefore, it is of utmost importance that new studies be conducted in this region to facilitate the monitoring of viral circulation and to investigate the impact of the new policies and programs related to HIV prevention, testing and treatment.

Some limitations must be considered in the interpretation of the present findings. First, the outcome and exposure data were collected simultaneously, and it was not possible to establish the causality of the factors studied. Second, the number of samples was too small to provide reasonable statistical power and definitive conclusions. Third, only HAART-naïve patients were subtyped. These patients did not represent the overall HIV population in the region, although the subtyped and unsubtyped groups did not show significant differences for several epidemiological characteristics (Table 2).

However, the large predominance of subtype C HIV-1 in a countryside region in South Brazil is noteworthy and provides further evidence that this subtype is widespread. Novel studies with larger numbers of samples should be conducted to determine the factors associated with the dissemination of subtype $\mathrm{C}$ and to develop prevention strategies to control the advance of the HIV-1/AIDS epidemic in South Brazil.

\section{CONFLICT OF INTEREST}

The authors declare that there is no conflict of interest.

\section{REFERENCES}

1. World Health Organization. (Internet). Global Report: UNAIDS Report on the Global AIDS Epidemic 2013 (update Nov 2013; cited 2014 Jul 8). Available at: http://www.unaids.org/en/media/ unaids/contentassets/documents/epidemiology/2013/gr2013/ UNAIDS_Global_Report_2013_en.pdf

2. Tebit DM, Arts EJ. Tracking a century of global expansion and evolution of HIV to drive understanding and to combat disease. Lancet Infect Dis 2011; 11:45-56.

3. Ministério da Saúde. Secretaria de Vigilância em Saúde. Departamento de DST, AIDS e Hepatites Virais. Boletim Epidemiológico - AIDS e DST. Brasília: Ministério da Saúde; 2014.

4. Gadelha SR, Shindo N, Cruz JN, Morgado MG, Galvão-Castro B. Molecular epidemiology of human immunodeficiency virus-1 in the state of Ceará, Northeast, Brazil. Mem Inst Oswaldo Cruz 2003; 98:461-463.

5. Teixeira SL, Bastos FI, Telles PR, Hacker MA, Brigido LF, Oliveira CAF, et al. HIV-1 infection among injection and exinjection drug users from Rio de Janeiro, Brazil: prevalence, estimated incidence and genetic diversity. J Clin Virol 2004; 31:221-226.

6. Sa Filho DJ, Sanabani S, Diaz RS, Munerato P, Brunstein A, Fusuma E, et al. Analysis of full-length human immunodeficiency virus type 1 genome reveals a variable spectrum of subtypes B and f recombinants in São Paulo, Brazil. AIDS Res Hum Retroviruses 2005; 21:145-151.

7. Pedroso C, Queiroz AT, Alcântara LC, Drexler JF, Diaz RS, Weyll $\mathrm{N}$, et al. High prevalence of primary antiretroviral resistance among HIV-1-infected adults and children in Bahia, a northeast state of Brazil. J Acquir Immune Defic Syndr 2007; 45:251-253.

8. Stefani MM, Pereira GA, Lins JA, Alcantara KC, Silveira AA, Viegas AA, et al. Molecular screening shows extensive HIV-1 genetic diversity in Central West Brazil. J Clin Virol 2007; 39:205209.

9. Souza AC, Oliveira CM, Rodrigues CL, Silva SA, Levi JE. Short communication: Molecular characterization of HIV type 1 BF pol recombinants from São Paulo, Brazil. AIDS Res Hum Retroviruses 2008; 24:1521-1525.

10. Machado LF, Ishak MO, Vallinoto AC, Lemos JA, Azevedo VN, Moreira MR, et al. Molecular epidemiology of HIV type 1 in northern Brazil: identification of subtypes $\mathrm{C}$ and $\mathrm{D}$ and the introduction of CRF02_AG in the Amazon region of Brazil. AIDS Res Hum Retroviruses 2009; 25:961-966.

11. Soares EA, Martínez AM, Souza TM, Santos AF, Da Hora V, Silveira J, et al. HIV-1 subtype C dissemination in southern Brazil. AIDS 2005; 19:S81-S86.

12. Simon D, Béria JU, Tietzmann DC, De Carli R, Stein AT, Lunge VR. Prevalence of HIV-1 subtypes in patients of an urban center in Southern Brazil. Rev Saude Publica 2010; 44:1094-1101.

13. Almeida SE, Medeiros RM, Junqueira DM, Gräf T, Passaes CBP, Bello G, et al. Temporal dynamics of HIV-1 circulating subtypes in distinct exposure categories in southern Brazil. Virol J 2012; 9:306.

14. Gräf T, Pinto AR. The increasing prevalence of HIV-1 subtype $\mathrm{C}$ in Southern Brazil and its dispersion through the continent. Virology 2013; 435:170-178.

15. Bello G, Zanotto PM, Iamarino A, Gräf T, Pinto AR, CoutoFernandez JC, et al. Phylogeographic analysis of HIV-1 subtype C dissemination in Southern Brazil. PLoS One 2012; 7:e35649.

16. Delatorre E, Couto-Fernandez JC, Guimarães ML, Vaz Cardoso LP, Alcantara KC, Stefani MMA, et al. Tracing the Origin and Northward Dissemination Dynamics of HIV-1 Subtype C in Brazil. PLoS One 2013; 8:e74072.

17. Cock KM, Weiss HA. The global epidemiology of HIV/AIDS. Trop Med Int Health 2000; 5:A3-A9. 
18. Ministério da Saúde. Secretaria de Vigilância em Saúde. Departamento de DST, AIDS e Hepatites Virais. Boletim Epidemiológico - AIDS e DST. Brasília: Ministério da Saúde; 2013.

19. Bello G, Passaes CPB, Guimarães ML, Lorete RS, Almeida SEM, Medeiros RM, et al. Origin and evolutionary history of HIV-1 subtype C in Brazil. AIDS 2008; 22:1993-2000.

20. Gräf T, Passaes CP, Ferreira LG, Grisard EC, Morgado MG, Bello G, et al. HIV-1 genetic diversity and drug resistance among treatment naïve patients from Southern Brazil: an association of HIV-1 subtypes with exposure categories. J Clin Virol 2011; $51: 186-191$

21. Oliveira T, Deforche K, Cassol S, Salminen M, Paraskevis D, See- bregts $\mathrm{C}$, et al. An automated genotyping system for analysis of HIV-1 and other microbial sequences. Bioinfomatics 2005; 21:3797-3800.

22. Siepel AC, Halpern AL, Macken C, Korber BT. A computer program designed to screen rapidly for HIV type 1 intersubtype recombinant sequences. AIDS Res Hum Retroviruses 1995; 11:1413-1416.

23. Guindon S, Gascuel O. A simple, fast, and accurate algorithm to estimate large phylogenies by maximum likelihood. Syst Biol 2003; 52:696-704

24. Edgar RC. MUSCLE: a multiple sequence alignment method with reduced time and space complexity. BMC Bioinformatics 2004; 5:113.

25. Lole KS, Bollinger RC, Paranjape RS, Gadkari D, Kulkarni SS, Novak NG, et al. Full-length human immunodeficiency virus type 1 genomes from subtype C-infected seroconverters in India, with evidence of intersubtype recombination. J Virol 1999; 73:152-160.

26. Grangeiro A, Escuder MM, Castilho EA. Magnitude and trend of the AIDS epidemic in Brazilian cities, from 2002 to 2006. Rev Saude Publica 2010; 44:430-440.

27. Pechansky F, Diemen LV, Kessler F, Boni R, Hilary Surrat H, Inciardi J. Predictors of HIV seropositive status in non-IV drug users at testing and counseling centers in Porto Alegre, Rio Grande do Sul, Brazil. Cad Saude Publica 2005; 21:266-274.

28. Reis CT, Czeresnia D, Barcellos C, Tassinari WS. Decentralization of the HIV/AIDS epidemic and inter-municipal flow of hospital admissions in the Zona da Mata, Minas Gerais State, Brazil: a spatial analysis. Cad Saude Publica 2008; 24:1219-1228.

29. Schneider IJC, Ribeiro C, Breda D, Skalinski LM, D'orsi E. Epidemiological profile of the clientele in HIV Testing and Counseling Centers in Santa Catarina State, Brazil, 2005. Cad Saude Publica 2008; 24:1675-1688.

30. Melo HMA, Leal MCC, Marques APO, Marino JG. Awareness about Aids among elderly males and young adults: a study of the perception of this disease. Cien Saude Colet 2012; 17:43-53

31. Brito AM, Castilho EA, Szwarcwald CL. AIDS and HIV infection in Brazil: a multifaceted epidemic. Rev Soc Bras Med Trop 2001; 34:207-217.

32. Fonseca MGP, Bastos FI. Twenty-five years of the AIDS epidemic in Brazil: principal epidemiological findings, 1980-2005. Cad Saude Publica 2007; 23:S333-S344.

33. Lazarini FM, Melchior R, González AD, Matsuo T. Trends in the epidemic of Aids cases in Southern Brazil from 1986 to 2008. Rev Saude Publica 2012; 46:960-968.

34. Matos MA, Caetano KAA, França DDS, Pinheiro RS, Moraes LC, Teles SA. Vulnerability to sexually transmitted infections in women who sell sex on the route of prostitution and sex tourism in central Brazil. Rev Lat Am Enfermagem 2013; 21:1-7.

35. Lana FCF, Lima AS. Prevention evaluation of HIV vertical transmission in Belo Horizonte, MG, Brazil. Rev Bras Enferm 2010; 63:587-594.
36. Lemos LM, Rocha TF, Conceição MV, Silva EL, Santos AH, Gurgel RQ. Evaluation of preventive measures for mother-to-child transmission of HIV in Aracaju, State of Sergipe, Brazil. Rev Soc Bras Med Trop 2012; 45:682-686.

37. Pires Araujo ES, Khalili Friedman R, Bastos Camacho LA, Derrico M, Ismério Moreira R, Amaral Calvet G, et al. Cascade of access to interventions to prevent HIV mother to child transmission in the metropolitan area of Rio de Janeiro, Brazil. Braz J Infect Dis 2014; $18: 252-260$

38. Gabriel R, Barbosa DA, Vianna LAC. Epidemiological profile of outpatients with HIV/AIDS at a school hospital-São Paulo city. Rev Lat Am Enfermagem 2005; 13:509-513.

39. Pereira BS, Costa MCO, Amaral MTR, Costa HS, Silva CAL, Sampaio VS. Factors associated with HIV/AIDS infection among adolescents and young adults enrolled in a Counseling and Testing Center in the State of Bahia, Brazil. Cien Saude Colet 2014; 19:747-758.

40. Simon D, Michita RT, Béria JU, Tietzmann DC, Stein AT, Lunge VR. Alcohol misuse and illicit drug use are associated with $\mathrm{HCV} /$ HIV co-infection. Epidemiol Infect 2014; 142:2616-2623.

41. Eyer-Silva WA, Couto-Fernandez JC, Morgado MG. Molecular epidemiology of HIV type 1 in inner Rio De Janeiro State, Brazil. AIDS Res Hum Retroviruses 2007; 23:303-308.

42. Librelotto CS, Simon D, Ikuta N, Lunge VR. Low prevalence of human immunodeficiency virus and hepatitis $\mathrm{C}$ virus co-infection in a medium size city in southern Brazil. Braz J Infect Dis 2014; 18:689-690.

43. Sanabani SS, Neto WK, Kalmar EM, Diaz RS, Janini LM, Sabino EC. Analysis of the near full length genomes of HIV-1 subtypes B, $\mathrm{F}$ and BF recombinant from a cohort of 14 patients in São Paulo, Brazil. Infect Genet Evol 2006; 6:368-377.

44. Santos AF, Sousa TM, Soares EA, Sanabani S, Martinez AM, Sprinz E, et al. Characterization of a new circulating recombinant form comprising HIV-1 subtypes C and B in southern Brazil. AIDS 2006; 20:2011-2019.

45. Brígido LF, Nunes CC, Oliveira CM, Knoll RK, Ferreira JL, Freitas CA, et al. HIV type 1 subtype $\mathrm{C}$ and CB Pol recombinants prevail at the cities with the highest AIDS prevalence rate in Brazil. AIDS Res Hum Retroviruses 2007; 23:1579-1586.

46. Rodrigues R, Manenti S, Romao PR, de Paula Ferreira JL, Batista JP, Siqueira AF, et al. Young pregnant women living with HIV/AIDS in Criciuma, Southern Brazil, are infected almost exclusively with HIV type 1 clade C. AIDS Res Hum Retroviruses 2010; 26:351-357.

47. Ariën KK, Vanham G, Arts EJ. Is HIV-1 evolving to a less virulent form in humans? Nat Rev Microbiol 2007; 5:141-151.

48. Abraha A, Nankya IL, Gibson R, Demers K, Tebit DM, Johnston E, et al.CCR5-andCXCR4-tropicsubtypeChumanimmunodeficiency virus type 1 isolates have a lower level of pathogenic fitness than other dominant group M subtypes: implications for the epidemic. J Virol 2009; 83:5592-5605.

49. Iordanskiy S, Waltke M, Feng Y, Wood C. Subtype-associated differences in HIV-1 reverse transcription affect the viral replication. Retrovirology 2010; 12:85.

50. Nunes CC, Matte MCC, Dias CF, Araújo LAL, Guimarães LSP, Almeida S, et al. The influence of HIV-1 subtypes C, CRF31_ $\mathrm{BC}$ and $\mathrm{B}$ on disease progression and initial virologic response to HAART in a Southern Brazilian cohort. Rev Inst Med Trop Sao Paulo 2014; 56:205-211.

51. Ministério da Saúde. Secretaria de Vigilância em Saúde. Departamento de DST, AIDS e Hepatites Virais. Protocolo clínico e diretrizes terapêuticas para o manejo da infecção pelo HIV em adultos. Brasília: Ministério da Saúde; 2013. 